\title{
MEREC ve WEDBA Yöntemleri ile Bir Lojistik Firmasının Yıllara Göre Performansının Değerlendirilmesi
}

\author{
Melike Toslak $^{1}$, Beyza Aktürk ${ }^{2}$, Alptekin Ulutaş ${ }^{3 *}$ \\ ${ }^{1}$ Sivas Cumhuriyet Üniversitesi, İktisadi ve İdari Bilimler Fakültesi, Uluslararası Ticaret ve Lojistik Bölümü, Sivas, Türkiye (ORCID: 0000-0002-0417-2796), \\ meliketoslak@outlook.com \\ ${ }^{2}$ Sivas Cumhuriyet Üniversitesi, İktisadi ve İdari Bilimler Fakültesi, Uluslararası Ticaret ve Lojistik Bölümü, Sivas, Türkiye (ORCID: 0000-0002-1172-2127), \\ akturk.byzaa@gmail.com \\ $3^{3 *}$ Sivas Cumhuriyet Üniversitesi, İktisadi ve İdari Bilimler Fakültesi, Uluslararası Ticaret ve Lojistik Bölümü, Sivas, Türkiye (ORCID: 0000-0002-8130-1301), \\ aulutas@cumhuriyet.edu.tr
}

(İlk Geliş Tarihi 23 Aralık 2022 ve Kabul Tarihi 31 Ocak 2022)

(DOI: 10.31590/ejosat.1041106)

ATIF/REFERENCE: Toslak, M., Aktürk, B. \& Ulutaş, A. (2022). MEREC ve WEDBA Yöntemleri ile Bir Lojistik Firmasının Yıllara Göre Performansının Değerlendirilmesi. Avrupa Bilim ve Teknoloji Dergisi, (33), 363-372.

$\ddot{O} \mathbf{z}$

Lojistik şirketlerinin performans değerlendirilmesinin yapılması ile bu şirketlerin faaliyetlerini gerçekleştirirken ne kadar verimli olduğu tespit edilebilir. Ayrıca bu şirketler performans değerlendirme sonucuna istinaden şirket hedeflerini ne derece gerçekleştirebildiğini görmüş olacaklardır ve performanslarını rakip firmalar ile kıyaslayarak güçlü ve zayıf yönlerini daha iyi fark edeceklerdir. Bu çalışmada bir lojistik işletmesinin yıllara göre performansı değerlendirilecektir. Değerlendirmede MEREC ve WEDBA yöntemleri kullanılacaktır. MEREC yöntemi ile kriter ağıllıkları bulunurken WEDBA yöntemi ile yıllar sıralanacaktır. Bu çalı̧̧ma ile MEREC yöntemi ulusal literatüre tanıtılıcaktır. Ayrıca MEREC ve WEDBA yöntemleri ilk defa birlikte kullanılacaktır. Böylece literatüre katkıda bulunulacaktır.

Anahtar Kelimeler: MEREC, WEDBA, Performans Değerlendirme.

\section{The Evaluation of the Performance of a Logistics Company by Years with MEREC and WEDBA Methods}

\begin{abstract}
With the performance evaluation of logistics companies, it can be determined how efficient these companies are while performing their activities. In addition, these companies will have seen to what extent they have achieved the company's goals based on the performance evaluation result, and they will be able to better realize their strengths and weaknesses by comparing their performance with rival companies. In this study, the performance of a logistics company according to years will be evaluated. MEREC and WEDBA methods will be used in the evaluation. While the criteria weights are found with the MEREC method, the years will be sorted with the WEDBA method. With this study, the MEREC method will be introduced to national literature. In addition, MEREC and WEDBA methods will be used together for the first time. Thus, it will contribute to the literature.
\end{abstract}

Keywords: MEREC, WEDBA, Performance Evaluation.

\footnotetext{
*Sorumlu Yazar: aulutas@,cumhuriyet.edu.tr
} 


\section{Giriş}

Lojistik kavramı genel olarak malzeme ve bilgi akışının üretim ve tüketim noktaları arasında doğru bir şekilde planlı gerçekleşmesi olarak tanımlanabilir. Firmalar, faaliyetlerini devam ettirebilmek için müşterilerin gereksinim ve taleplerini uygun bir şekilde kısa zamanda karşılamak durumundadırlar. Lojistiğin en önemli amacı alıcılara doğru ve hızlı bir şekilde ürün dağıtımını gerçekleştirmektir (Ulutaş, 2019). Lojistik faaliyetler, firmalar ve müşteriler arasında değer yaratmanın yanı sıra firmaların başarısının artırılmasında ve ölçülmesinde fazlasıyla önemli hale gelmiştir.

Günümüzde firmalar arasında rekabetin artmasıyla firmaların lojistik hizmetlerinde müşteri ihtiyaçlarını tam ve sürdürebilir şekilde gerçekleştirmesi gerekir. Firmalar lojistik faaliyetlerini doğru ve sürdürülebilir olması için bazen dış kaynak kullanımı yaparak, lojistik hizmeti sunan işletmelerden lojistik hizmeti alırlar. Lojistik hizmeti sağlayan işletmelerin doğru seçimi lojistik hizmeti almak isteyen firmalar için önemlidir. Bu seçim işleminde işletmelerin performanslarının incelenmesi, firmalar açısından gereklidir. Lojistik işletmelerinin performans ölçümünün yapılması ile bu işletmelerin faaliyetlerini gerçekleştirirken ne kadar verimli olduğu tespit edilebilir. Ayrıca bu işletmeler performans ölçümü sonucuna göre hedeflerini ne derece gerçekleştirebildiğini görmüş olacaklar ve rakip firmalara göre güçlü ve zayıf yönlerini daha iyi fark edeceklerdir.

Detaylı performans ölçümünün yapılması, işletmelerin başarıya ulaşması için bir esastır. Performans ölçüm yönteminin temel görevi katma değerli gösterimlerin yapısına dair öngörü yakalamak olup, ayrıca işletmelerin faaliyetlerde amaçlara ulaşma doğrultusunda devamlılığını sağlamada ve faaliyet stratejilerinin başarısı ile ilgili önemli sonuçların sağlanmasını da içermektedir. Dolayısıyla performans ölçümü sadece operasyonel ve rekabetçi stratejileri açıklama yükümlülüğü olan yöneticiler için değil, ayrıca stratejileri gerçekleştirmek mecburiyetinde olan çalışanların da hareketlerini oluşturmaktadır (Fawcett, 1998). Performans ölçümü ile yapılmış çok fazla çalışma bulunmaktadır ve bu çalışmalarda genellikle regresyon analizi ve bilançolardaki mali rasyolara dayalı oran analizi kullanılmaktadır (Çakır ve Perçin, 2013). Çok kriterli karar verme (ÇKKV) yöntemleri, son yıllarda performans ölçümünde sıklıkla kullanılan yöntemler haline gelmiştir. Performans ölçümlerinde birden fazla kriterin ve alternatifin göz önüne alınmasından dolayı ÇKKV yöntemleri istatistiksel yöntemlere oranla son yıllarda daha çok kullanılmaktadır. Bu çalışmada da performans ölçümü yapılacağı için ÇKKV yöntemleri kullanılmıştır.

$\mathrm{Bu}$ çalışmada kullanılan veriler Fortune 500 Türkiye dergisinden alınmıştır. Bu çalışmada Ekol lojistiğin 2010-2020 yılları arasındaki performans değerleri analiz edilecektir. Çalışmada Ekol lojistiğin yıllara göre performansı ölçülerek incelenmiş ve performans ölçüm analizi yapılırken MEREC ve WEDBA yöntemleri kullanılmıştır. Her iki yöntem ile ilgili az sayıda Türkçe çalışma olmasından dolayı bu iki yöntem kullanılmıştır. MEREC yöntemi, kriter ağırlıklarını hesaplamak için her bir kriterin alternatiflerin toplam performansı üzerindeki etkisinin çıkarılmasında kullanılan bir objektif ağırlıklandırma yöntemidir (Ghorabaee, 2021). WEDBA yöntemi ise alternatiflerin sıralamasında kullanılan bir ÇKKV yöntemidir. En uygun durum ideal nokta olarak gösterilirken en düşük durum anti-ideal nokta olarak açıklanır (Demir, 2021). Çalışmada bu yöntemler birlikte kullanılarak Türkçe literatüre katkı sunulacaktır.

Literatürde birçok çalışmada lojistik firmalarının performansları ÇKKV yöntemleri kullanılarak ölçülmüştür. Tablo 1 'de bu çalışmalar özetlenmiştir.

Tablo 1. Lojistik Firmalarının Performans Ölçümü ile İlgili Literatür Taraması (Table 1. Literature Review on Performance Measurement of Logistics Firms)

\begin{tabular}{|c|c|c|}
\hline Yazarlar & Yöntemler & Konu \\
\hline $\begin{array}{c}\text { Görener } \\
\text { (2009) }\end{array}$ & ANP & $\begin{array}{l}\text { İmalat sanayindeki } \\
\text { bir işletmenin } \\
\text { tedarikçi seçim } \\
\text { sorununa çözüm } \\
\text { aranmiştır. }\end{array}$ \\
\hline $\begin{array}{c}\text { Chen vd. } \\
\text { (2010) }\end{array}$ & $\begin{array}{c}\text { Dilsel } \\
\text { PROMETHEE }\end{array}$ & $\begin{array}{c}\text { Üçüncü parti } \\
\text { lojistik firması } \\
\text { seçimi yapılmıştır. }\end{array}$ \\
\hline $\begin{array}{l}\text { Özbek ve } \\
\text { Eren } \\
\text { (2012) }\end{array}$ & AHP & $\begin{array}{c}\text { Üçüncü parti } \\
\text { lojistik firması } \\
\text { seçimi yapılmıştır. }\end{array}$ \\
\hline $\begin{array}{l}\text { Çakır ve } \\
\text { Perçin } \\
\text { (2013) }\end{array}$ & $\begin{array}{c}\text { CRITIC, } \\
\text { SAW, TOPSIS } \\
\text { ve VIKOR }\end{array}$ & $\begin{array}{c}\text { Fortune } 500 \\
\text { Türkiye'de yer } \\
\text { alan } 10 \text { lojistik } \\
\text { işletmenin } \\
\text { performansı } \\
\text { değerlendirilmiştir. }\end{array}$ \\
\hline $\begin{array}{c}\text { Ishizaka } \\
\text { (2014) }\end{array}$ & $\begin{array}{c}\text { Bulanık AHP } \\
\text { ve AHP }\end{array}$ & $\begin{array}{c}\text { Tedarikçi seçimi } \\
\text { ve performans } \\
\text { analizi yapılmıştır. }\end{array}$ \\
\hline $\begin{array}{l}\text { Jayant ve } \\
\text { Singh } \\
(2015)\end{array}$ & $\begin{array}{l}\text { AHP ve } \\
\text { VIKOR }\end{array}$ & $\begin{array}{c}9 \text { üçüncü parti } \\
\text { lojistik firması } 10 \\
\text { kritere göre } \\
\text { değerlendirilmiştir. }\end{array}$ \\
\hline $\begin{array}{c}\text { Aguezzoul } \\
\text { ve Pires } \\
(2016)\end{array}$ & ELECTRE I & $\begin{array}{c}\text { Alternatif olarak } \\
13 \text { üçüncü parti } \\
\text { lojistik firması } \\
\text { değerlendirilmiştir. }\end{array}$ \\
\hline $\begin{array}{c}\text { Ayaydın } \\
v d .(2017)\end{array}$ & $\begin{array}{c}\text { Gri İlişkisel } \\
\text { Analiz }\end{array}$ & $\begin{array}{c}8 \text { kriter baz } \\
\text { alınarak Fortune } \\
500 \text { Türkiye'de } \\
\text { yer alan } 10 \text { lojistik } \\
\text { şirketin } \\
\text { performansı analiz } \\
\text { edilmiştir. }\end{array}$ \\
\hline $\begin{array}{l}\text { Eren ve } \\
\text { Gür } \\
\text { (2017) }\end{array}$ & $\begin{array}{l}\text { AHP ve } \\
\text { TOPSIS }\end{array}$ & $\begin{array}{l}\text { Bir online alışveriş } \\
\text { sitesi için üçüncü } \\
\text { parti lojistik } \\
\text { firması seçimi } \\
\text { yapılmıştır. } \\
\end{array}$ \\
\hline $\begin{array}{l}\text { Livd. } \\
(2018)\end{array}$ & $\begin{array}{c}\text { Hibrit Bilgi } \\
\text { Destekli } \\
\text { ÇKKV }\end{array}$ & $\begin{array}{c}5 \text { üçüncü parti } \\
\text { lojistik firması } \\
\text { değerlendirilmiştir. }\end{array}$ \\
\hline $\begin{array}{c}\text { Rezaei vd. } \\
\text { (2018) }\end{array}$ & BWM & $\begin{array}{c}\text { Lojistik } \\
\text { performans } \\
\text { indeksi } \\
\text { göstergelerinin } \\
\text { ağırlıkları } \\
\text { hesaplanmıştır. } \\
\end{array}$ \\
\hline
\end{tabular}




\begin{tabular}{|c|c|c|}
\hline $\begin{array}{l}\text { Ulutaş } \\
\text { (2019) }\end{array}$ & $\begin{array}{l}\text { EDAS ve } \\
\text { Entropi }\end{array}$ & $\begin{array}{l}7 \text { firmanın lojistik } \\
\text { performans } \\
\text { değerlendirilmiştir. }\end{array}$ \\
\hline $\begin{array}{l}\text { Kisa ve } \\
\text { Ayçin } \\
\text { (2019) }\end{array}$ & $\begin{array}{c}\text { SWARA ve } \\
\text { EDAS }\end{array}$ & $\begin{array}{l}\text { OECD ülkelerinin } \\
\text { lojistik } \\
\text { performansı analiz } \\
\text { edilmiştir. }\end{array}$ \\
\hline $\begin{array}{l}\text { Yalçın ve } \\
\text { Ayvaz } \\
(2020)\end{array}$ & $\begin{array}{c}\text { Bulanık AHP } \\
\text { ve Bulanık } \\
\text { TOPSIS }\end{array}$ & $\begin{array}{c}5 \text { ülkenin lojistik } \\
\text { performansı } 6 \\
\text { kritere göre } \\
\text { değerlendirilmiştir. }\end{array}$ \\
\hline $\begin{array}{l}\text { Mercangoz } \\
v d .(2020)\end{array}$ & COPRAS-G & $\begin{array}{c}28 \mathrm{AB} \text { ülkesinin } \\
\text { ve } 5 \text { aday ülkenin } \\
\text { lojistik } \\
\text { performansları } \\
\text { değerlendirilmiştir. }\end{array}$ \\
\hline $\begin{array}{c}\text { Khan vd. } \\
(2020)\end{array}$ & Bulanık AHP & $\begin{array}{c}\text { Bir kurye } \\
\text { şirketinin lojistik } \\
\text { performansı } \\
\text { değerlendirilmiştir. }\end{array}$ \\
\hline $\begin{array}{l}\text { Jovčić ve } \\
\text { Průša } \\
\text { (2021) }\end{array}$ & $\begin{array}{l}\text { ARAS, } \\
\text { Entropi ve } \\
\text { CRITIC }\end{array}$ & $\begin{array}{c}\text { Üçüncü parti } \\
\text { lojistik firması } \\
\text { seçimi yapılmıştır. }\end{array}$ \\
\hline $\begin{array}{c}\text { Senir } \\
(2021)\end{array}$ & $\begin{array}{l}\text { CRITIC ve } \\
\text { COPRAS }\end{array}$ & $\begin{array}{c}\text { Türkiye ve AB } \\
\text { ülkelerinin yerel } \\
\text { lojistik } \\
\text { performansları } \\
\text { kıyaslanmıştır. }\end{array}$ \\
\hline $\begin{array}{c}\text { Aydin vd. } \\
\text { (2021) }\end{array}$ & $\begin{array}{l}\text { Nötrosofik } \\
\text { TOPSIS }\end{array}$ & $\begin{array}{c}\text { Dördüncü parti } \\
\text { lojistik firması } \\
\text { değerlendirilmiştir. }\end{array}$ \\
\hline $\begin{array}{l}\text { Yuan vd. } \\
\text { (2021) }\end{array}$ & $\begin{array}{l}\text { Olasiliklı Dil } \\
\text { altında } \\
\text { DEMATEL ve } \\
\text { COPRAS }\end{array}$ & $\begin{array}{c}\text { Üçüncü parti } \\
\text { lojistik firması } \\
\text { seçimi yapılmıştır. }\end{array}$ \\
\hline $\begin{array}{c}\text { Akpınar } \\
\text { (2021) }\end{array}$ & $\begin{array}{c}\text { SWARA ve } \\
\text { WASPAS }\end{array}$ & $\begin{array}{c}\text { Üçüncü parti } \\
\text { lojistik firması } \\
\text { seçimi yapılmıştır. }\end{array}$ \\
\hline $\begin{array}{l}\text { Ulutaş } \\
\text { (2021) }\end{array}$ & $\begin{array}{c}\text { Gri SWARA } \\
\text { ve Gri } \\
\text { CODAS } \\
\end{array}$ & $\begin{array}{c}\text { Üçüncü parti } \\
\text { lojistik firması } \\
\text { seçimi yapılmıştır. }\end{array}$ \\
\hline
\end{tabular}

$\mathrm{Bu}$ çalışmada MEREC ve WEDBA yöntemleri birlikte kullanılacaktır. MEREC yöntemi literatüre 2021 yılında Ghorabaee ve arkadaşları tarafindan tanıtılmıştır (Ghorabaee vd., 2021). Bu yüzden MEREC yöntemi ile yapılan çalışma sayısı azdır. Bunlardan biri Goswami vd. (2021), MEREC yöntemi ile PIV yöntemini birleştirerek Hindistan'daki bir yer için yenilenebilir enerji santralini seçmişlerdir. Ghorabaee (2021), Değiştirilmiş SWARA, MEREC ve WASPAS yöntemleri ile İran'da bulunan bir şirketin dağıtım merkezleri için yer alternatiflerini değerlendirmiştir.

WEDBA yöntemi çok yeni bir ÇKKV yöntemi olmamasına rağmen bu yöntemle yapılan çalışma sayısı azdır. Rao ve Singh (2012), WEDBA yönteminin uygulanabilirliğini ölçmek için üç tane örnek kullanmışlardır. Diğer bir çalışmada Garg (2017), Bulanık AHP, COPRAS ve WEDBA yöntemlerini kullanarak en iyi e-Öğrenme websitesini beş alternatif arasından belirlemiştir. Al-Hawari vd. (2019), WEDBA yönteminin bulanık versiyonunu geliştirmişlerdir ve bu yöntemin uygulanabilirliğini iki sayısal örnek ile değerlendirmişlerdir. Jain ve Ajmera (2019), AHP,
Entropi ve WEDBA yöntemlerini birlikte kullanarak esnek üretim sistemlerinin esnekliğini sıralamışlardır. Ulutaş (2020), WEDBA yöntemi ile PSI yöntemini birleştirerek istifleyici seçimi yapmıştır. Basar ve Tolga (2020), Bulanık WEDBA yöntemi ile dikey tarımda akıllı sistem seçimi yapmışlardır. Demir (2021), CRITIC ve WEDBA yöntemleri ile vakıf üniversitelerinin akademik performansını değerlendirmiştir.

Literatür taramasına göre MEREC yöntemi yeni geliştirildiği için bu yöntemle ilgili yayın sayısı azdır. Ayrıca WEDBA yöntemi de çok az sayıdaki yayında görülmektedir. Bundan dolayı bu çalışmada MEREC yöntemi ulusal literatüre tanıtılacak ve WEDBA yöntemi ile birleştirilerek yeni bir hibrit ÇKKV modeli oluşturulacaktır.

\section{Materyal ve Metot}

$\mathrm{Bu}$ çalışmada MEREC yöntemi kriter ağırlıklarının bulunmasında kullanılacaktır. WEDBA yöntemi ile yıllar siralanacaktır.

\subsection{MEREC}

MEREC yönteminin adımları aşağıda gösterilmiştir (Ghorabaee vd., 2021; Ghorabaee, 2021):

Adım 1: Karar matrisinin oluşturulması. Eşitlik 1, karar matrisini göstermektedir.

$$
D=\left[d_{i j}\right]_{m \times n}
$$

Eşitlik 1'de gösterilen $d_{i j}$ değeri $i$ alternatifinin $j$ kriterindeki değerini göstermektedir. Bu değer pozitif bir değer olmak zorundadır. Eğer pozitif değilse uygun yöntemler kullanılarak pozitif hale getirilmelidir.

Adım 2: Karar matrisi aşağıdaki eşitlikler yardımı ile normalize edilir. Eşitlik 2 ile fayda kriterleri, Eşitlik 3 ile maliyet kriterleri normalize edilir.

$$
\begin{aligned}
& d_{i j}^{*}=\frac{\min d_{i j}}{d_{i j}} \\
& d_{i j}^{*}=\frac{d_{i j}}{\operatorname{makd}_{i j}}
\end{aligned}
$$

Adım 3: Alternatiflerin toplam performans değeri $\left(S_{i}\right)$ Eşitlik 4 ile bulunur.

$$
S_{i}=\ln \left(1+\left(\frac{1}{m} \sum_{j}\left|\ln \left(d_{i j}^{*}\right)\right|\right)\right)
$$

Adım 4: Her bir kriterin değeri çıkartılarak alternatiflerin performans değerindeki değişiklikler $\left(S_{i j}^{\prime}\right)$ Eşitlik 5 ile hesaplanır.

$$
S_{i j}^{\prime}=\ln \left(1+\left(\frac{1}{m} \sum_{k, k \neq j}\left|\ln \left(d_{i k}^{*}\right)\right|\right)\right)
$$

Adım 5: Mutlak sapmaların toplamı $\left(E_{j}\right)$ hesaplanır. $\mathrm{Bu}$ adımda kriterin kendisi üzerindeki çıkartılma etkisi ölçülür.

$$
E_{j}=\sum_{i}\left|S_{i j}^{\prime}-S_{i}\right|
$$

Adım 6: Kriterlerin ağırlığı $\left(w_{j}\right)$ aşağıdaki gibi hesaplanır.

$$
w_{j}=\frac{E_{j}}{\sum_{k} E_{k}}
$$

\subsection{WEDBA}

WEDBA yönteminin adımları şu şekildedir (Rao ve Singh, 2011; Jain ve Ajmera, 2019). 
Adım 1: Karar matrisi düzenlenir. Karar matrisi, Eşitlik 1'de sunulmuştur.

Adım 2: Karar matrisindeki değerler normalize edilir. Normalizasyon işlemleri eşitlikler 2 ve 3 'te gösterilmiştir. Eşitlik 2 kullanılarak maliyet kriterleri normalize edilirken, Eşitlik 3 ile fayda kriterleri normalize edilir.

Adım 3: Normalize karar matrisindeki değerler Eşitlik 8 ile standardize edilir.

$$
t_{i j}=\frac{d_{i j}^{*}-\mu_{j}}{\sigma_{j}}
$$

Eşitlik 8'de gösterilen $\mu_{j}$ ve $\sigma_{j}$ sırasıyla $j$. kriterin ortalama değerini ve standart sapmasını göstermektedirler. Eşitlik 9 ile $\mu_{j}$, Eşitlik 10 ile $\sigma_{j}$ hesaplanır.

$$
\begin{aligned}
& \mu_{j}=\frac{\sum_{i=1}^{m} d_{i j}^{*}}{m} \\
& \sigma_{j}=\sqrt{\frac{\sum_{i=1}^{m}\left(d_{i j}^{*}-\mu_{j}\right)^{2}}{m}}
\end{aligned}
$$

Adım 4: İdeal $\left(t_{i j}^{+}\right)$ve anti-ideal $\left(t_{i j}^{-}\right)$değerler hesaplanır.

$$
\begin{gathered}
t_{i j}^{+}=\max \left(t_{i j}\right) \\
t_{i j}^{-}=\min \left(t_{i j}\right)
\end{gathered}
$$

Adım 5: Her bir alternatifin Ağırlıklı Öklid Uzaklıkları $\left(W E D_{i}^{+}, W E D_{i}^{-}\right)$ve İndeks Skoru $\left(I S_{i}\right)$ hesaplanır.

$$
\begin{aligned}
& W E D_{i}^{+}=\sqrt{\sum_{j=1}^{n}\left\{w_{j}\left(t_{i j}-t_{i j}^{+}\right)\right\}^{2}} \\
& W E D_{i}^{-}=\sqrt{\sum_{j=1}^{n}\left\{w_{j}\left(t_{i j}-t_{i j}^{-}\right)\right\}^{2}} \\
& I S_{i}=\frac{W E D_{i}^{-}}{W E D_{i}^{-}+W E D_{i}^{+}}
\end{aligned}
$$

En yüksek İndeks Skoruna sahip alternatif en iyi alternatif olarak belirlenir.

\section{Araştırma Sonuçları ve Tartışma}

$\mathrm{Bu}$ çalışmada Ekol Lojistik 4.0 işletmesinin Fortune 500 Türkiye (https://www.fortuneturkey.com/fortune500) internet sitesinde yer alan 2010-2020 y1llarına ait verileri değerlendirilmiştir. Şirketin 2020 yılına ait cirosu $521.892 .982 €$ olarak (https://www.ekol.com/tr/kurumsal/rakamlarla-ekol-

lojistik/ciro/). Şirketin yıllara göre performansı değerlendirilirken sekiz kriter göz önüne alınacaktır. Bu kriterler şunlardır: Net Satış (KRT 1), Net Satış Değişimi (KRT 2), Faiz, Vergi Öncesi Kâr (KRT 3), Faiz, Vergi Öncesi Kâr Değişimi (KRT 4), Aktif Toplam (KRT 5), Özkaynak (KRT 6), İhracat (KRT 7), ve Çalışan Sayısı (KRT 8). Bu kriterlerden sadece KRT 8 (Çalışan Sayısı) kriteri maliyet kriteri olarak alınmış olup, diğer kriterler fayda kriterleri olarak alınmıştır. Şirketin, KRT 4 kriterinde 2019 yılındaki ve 2010 yılındaki verileri eksi değerler olduğu için en küçük eksi değerin $(-49,4)$ mutlağı alınıp bu değere 1 eklenmiştir. Bulunan bu değer KRT 4 kriterinin altındaki bütün değerlere eklenmiştir. Tablo 2'de şirketin 2010-2020 yılları arasındaki verileri başka bir ifade ile karar matrisi sunulmuştur.

Tablo 2'de gösterilen karar matrisindeki değerler Eşitlik 2 ve Eşitlik 3 ile normalize edilir. Tablo 3, normalize karar matrisini sunmaktadır. Eşitlik 4 ile alternatiflerin toplam performans değerleri $\left(S_{i}\right)$ bulunur. Tablo 4 , toplam performans değerlerini göstermektedir. Eşitlik 5 ile $S_{i j}^{\prime}$ değerleri bulunur. Tablo 5, bu değerleri göstermektedir. Son olarak Eşitlik 6 ile mutlak sapmaların toplamı $\left(E_{j}\right)$ ve Eşitlik 7 ile kriterlerin ağırlıkları $\left(w_{j}\right)$ bulunur. Bu değerler, Tablo 6'da gösterilmiştir. Bulunan kriter ağırlıkları WEDBA yöntemine aktarılır.

WEDBA yönteminde Tablo 2'de gösterilen karar matrisine Eşitlik 2 (Maliyet) ve Eşitlik 3 (Fayda) uygulanır ve normalize karar matrisi WEDBA yöntemi için elde edilir. Tablo 7, WEDBA yöntemi için normalize karar matrisini göstermektedir. Eşitlik 8 ile Tablo 7'de gösterilen normalize karar matrisi standardize edilir. Tablo 8, standardize karar matrisini göstermektedir. Son olarak her bir alternatifin Ağırlıklı Öklid Uzaklıkları $\left(W E D_{i}^{+}\right.$, $\left.W E D_{i}^{-}\right)$ve İndeks Skoru $\left(I S_{i}\right)$, eşitlikler 13-15 ile hesaplanır. Tablo 9, sonuçları göstermektedir. Tablo 9'a göre şirketin yıllara göre performansı şu şekilde gerçekleşmiştir: 2020 > 2014 > 2011> $2013>2018>2017>2015>2012>2016>2019>2010$. Sonuç olarak en iyi performansın görüldüğü y1l 2020 yılı olarak belirlenmiştir. Şirketin en kötü performans gösterdiği yıl ise 2010 yılı olarak belirlenmiştir. 2020 yılında küresel pandemi (COVID19) ortaya çıkmasına rağmen 2020 yılında şirket en iyi performansa sahip olmuştur. WEDBA yönteminin doğru sonuçlara ulaşıp ulaşmadığını tespit etmek için Tablo 2'de gösterilen karar matrisine MOORA, WASPAS ve ROV yöntemleri uygulanmıştır. Bu yöntemlerin sonuçları Tablo 10'da gösterilmiştir. WEDBA yöntemi ile bulunan sıralamalar ve MOORA, WASPAS ve ROV yöntemleri ile bulunan siralamalar Spearman Korelasyonu ile karşılaştırılmıştır. Korelasyon sonuçlarına göre WEDBA-MOORA yöntemleri arasında 0,864, WEDBA-WASPAS arasinda 0,809 ve WEDBA-ROV arasında 0,855 korelasyon değerleri bulunmuştur. Korelasyon sonuçlarına göre WEDBA yöntemi doğru sonuçlara ulaşmıştır.

Kriter ağırlıklarının sonuca etkisini göstermek için duyarlılık analizi yapılmıştır. Duyarlılık analizi için belirlenen kriter ağırlıkları ve senaryolar Tablo 11'de gösterilmiştir. Duyarlılık analizinin sonuçları Şekil 1'de gösterilmiştir. Görüleceği üzere kriter ağırlıklarının değişmesi alternatiflerin sıralamasını değiştirmiştir. Örneğin 2020 yılı Senaryo 1 ve Senaryo 4'te 1. siradaki yerini korurken Senaryo 2'de 4. sirada Senaryo 3'te ise 2. sırada yer almaktadır. Aynı şekilde analiz sonucunda son sırada yer alan 2010 yılı Senaryo 2 ve Senaryo 4'te yerini korurken Senaryo 1'de 8. sirada yer alırken Senaryo 3'te ise 5.sirada yer almaktadır. COVID-19 sürecinden önceki yıl olan 2019 yılına baktığımızda bu yıl Senaryo 1 ve Senaryo 4'te 3.sırada yer alırken Senaryo 2'de 10.sırada ve Senaryo 3'te ise 9.sırada yer almıştır. Yılların sıralaması senaryolardaki ağırlıkların etkisi ile en az bir kere değişmiştir. Buradan WEDBA yönteminin kriter ağırlıklarında oluşan değişikliklere karşı duyarlı olduğu sonucuna varılmıştır. 
Tablo 2. Karar Matrisi (Table 2. Decision Matrix)

\begin{tabular}{|c|c|c|c|c|}
\hline$\underbrace{\text { Kriterler }}_{\text {Yıllar }}$ & KRT 1 & KRT 2 & KRT 3 & KRT 4 \\
\hline 2020 & 3900651680,90 & 16,72875379 & 272825746,34 & 292,64232153226 \\
\hline 2019 & 3341637376 & 0,369811088 & 79717128,00 & 20,53451194763 \\
\hline 2018 & 3329325175,74 & 35,014569 & 113663193,83 & 106,101173 \\
\hline 2017 & 2465900679,30 & 31,133346 & 25120100,48 & 120,46811 \\
\hline 2016 & 1880452807,90 & 24,367635 & 50263958,27 & 52,745336 \\
\hline 2015 & 1512011385,90 & 29,766944 & 49112114,18 & 97,270537 \\
\hline 2014 & 1165174538 & 26,8 & 33439051,00 & 245,5 \\
\hline 2013 & 918880247,71 & 41,9062150 & 11332614,19 & 141,592793 \\
\hline 2012 & 629374958 & 27,7345460 & 12798185,00 & 97,240266 \\
\hline 2011 & 509199165 & 62,6561130 & 8715719,00 & 55,548244 \\
\hline 2010 & 313052584 & 4,3 & 8288742,00 & 1 \\
\hline$\underbrace{\text { Kriterler }}_{\text {Yıllar }}$ & KRT 5 & KRT 6 & KRT 7 & KRT 8 \\
\hline 2020 & 3551160275,83 & 768933278,61 & 7719 & 3203936672,52 \\
\hline 2019 & 2813050112,00 & 468627424,00 & 7827 & 2343131392,00 \\
\hline 2018 & 2543748100,61 & 442006011,52 & 8148 & 2666504963,55 \\
\hline 2017 & 1680906559,56 & 321199930,96 & 7989 & 1944136610,08 \\
\hline 2016 & 1318687488,69 & 247043820,95 & 7055 & 857582948,46 \\
\hline 2015 & 1023182757,72 & 199662614,86 & 6580 & 380475336,30 \\
\hline 2014 & 696645914,00 & 180867267,00 & 5576 & 313188884,00 \\
\hline 2013 & 670784360,24 & 191434273,01 & 4710 & 234048165,22 \\
\hline 2012 & 361700526,00 & 154790029,00 & 2351 & 152663304,00 \\
\hline 2011 & 323696292,00 & 149018889,00 & 2130 & 138282291,00 \\
\hline 2010 & 277709387,00 & 151847807,00 & 1491 & 93052437,00 \\
\hline
\end{tabular}

Tablo 3. Normalize Karar Matrisi (MEREC) (Table 3. Normalised Decision Matrix (MEREC))

\begin{tabular}{c|c|c|c|c}
\hline Kriterler & KRT 1 & KRT 2 & KRT 3 & KRT 4 \\
\hline 2020 & 0,08 & 0,022 & 0,030 & 0,003 \\
\hline 2019 & 0,094 & 1 & 0,104 & 0,049 \\
\hline 2018 & 0,094 & 0,011 & 0,073 & 0,009 \\
\hline 2017 & 0,127 & 0,012 & 0,33 & 0,008 \\
\hline 2015 & 0,166 & 0,015 & 0,165 & 0,019 \\
\hline 2014 & 0,207 & 0,012 & 0,169 & 0,004 \\
\hline 2013 & 0,269 & 0,014 & 0,248 & 0,007 \\
\hline 2012 & 0,341 & 0,009 & 0,731 & 0,018 \\
\hline 2011 & 0,497 & 0,013 & 0,648 & 1 \\
\hline Kriterler & 0,615 & 0,006 & 0,951 & KRT 8 \\
\hline Yıllar & 1 & 0,086 & 1 & 0,029 \\
\hline 2020 & KRT 5 & KRT 6 & KRT 7 & 0,04 \\
\hline 2019 & 0,078 & 0,194 & 0,947 & 0,035 \\
\hline 2018 & 0,099 & 0,318 & 0,961 & 0,048 \\
\hline 2017 & 0,109 & 0,337 & 1 & 0,109 \\
\hline 2016 & 0,165 & 0,464 & 0,98 & 0,245 \\
\hline 2015 & 0,211 & 0,603 & 0,866 & 0,297 \\
\hline
\end{tabular}


Avrupa Bilim ve Teknoloji Dergisi

\begin{tabular}{c|c|c|c|c}
\hline 2013 & 0,414 & 0,778 & 0,578 & 0,398 \\
\hline 2012 & 0,768 & 0,963 & 0,289 & 0,61 \\
\hline 2011 & 0,858 & 1 & 0,261 & 0,673 \\
\hline 2010 & 1 & 0,981 & 0,183 & 1 \\
\hline
\end{tabular}

Tablo 4. Toplam Performans Değerleri (MEREC) (Table 4. Total Performance Values (MEREC))

\begin{tabular}{c|c}
\hline Yillar & $\boldsymbol{S}_{\boldsymbol{i}}$ \\
\hline 2020 & 1,141 \\
\hline 2019 & 0,835 \\
\hline 2018 & 1,063 \\
\hline 2017 & 0,971 \\
\hline 2016 & 0,905 \\
\hline 2015 & 0,883 \\
\hline 2014 & 0,868 \\
\hline 2013 & 0,807 \\
\hline 2012 & 0,743 \\
\hline 2011 & 0,718 \\
\hline 2010 & 0,321 \\
\hline
\end{tabular}

Tablo 5. $S_{i j}^{\prime}$ Değerleri (Table 5. $S_{i j}^{\prime}$ Values)

\begin{tabular}{c|c|c|c|c}
\hline \multicolumn{1}{c|}{ Kriterler } & KRT 1 & KRT 2 & KRT 3 & KRT 4 \\
\hline 2020 & 1,065 & 1,024 & 1,034 & 0,957 \\
\hline 2019 & 0,737 & 0,835 & 0,742 & 0,709 \\
\hline 2018 & 0,986 & 0,911 & 0,978 & 0,903 \\
\hline 2017 & 0,897 & 0,806 & 0,932 & 0,789 \\
\hline 2016 & 0,836 & 0,737 & 0,836 & 0,747 \\
\hline 2015 & 0,822 & 0,701 & 0,814 & 0,693 \\
\hline 2013 & 0,817 & 0,69 & 0,813 & 0,631 \\
\hline 2012 & 0,763 & 0,596 & 0,795 & 0,583 \\
\hline 2011 & 0,712 & 0,535 & 0,724 & 0,521 \\
\hline 2010 & 0,697 & 0,461 & 0,716 & 0,522 \\
\hline Kriterler & 0,321 & 0,145 & 0,321 & 0,321 \\
\hline Yillar & & & & \\
\hline 2020 & KRT 5 & KRT 6 & KRT 7 & KRT 8 \\
\hline 2019 & 1,064 & 1,093 & 1,14 & 1,033 \\
\hline 2018 & 0,74 & 0,789 & 0,834 & 0,7 \\
\hline 2017 & 0,991 & 1,029 & 1,063 & 0,952 \\
\hline 2016 & 0,907 & 0,944 & 0,97 & 0,861 \\
\hline 2015 & 0,846 & 0,886 & 0,899 & 0,82 \\
\hline 2014 & 0,833 & 0,872 & 0,875 & 0,829 \\
\hline 2013 & 0,832 & 0,861 & 0,853 & 0,821 \\
\hline 2012 & 0,771 & 0,797 & 0,785 & 0,769 \\
\hline 2011 & 0,731 & 0,741 & 0,688 & 0,721 \\
\hline 2010 & 0,712 & 0,718 & 0,657 & 0,701 \\
\hline & 0,321 & 0,32 & 0,203 & 0,321 \\
\hline
\end{tabular}

Tablo 6. Mutlak Sapmaların Toplamı ve Kriterlerin Ağırlıkları (Table 6. Sum of Absolute Deviations and Weights of Criteria)

\begin{tabular}{c|c|c|c|c}
\hline Kriterler & KRT 1 & KRT 2 & KRT 3 & KRT 4 \\
\hline$E_{j}$ & 0,602 & 1,814 & 0,55 & 1,879 \\
\hline
\end{tabular}


European Journal of Science and Technology

\begin{tabular}{c|c|c|c|c}
\hline$w_{j}$ & 0,092 & 0,276 & 0,084 & 0,286 \\
\hline \multirow{2}{\text{Kriterler}}{} & KRT 5 & KRT 6 & KRT 7 & \multirow{2}{*}{ KRT 8 } \\
\hline$E_{j}$ & 0,507 & 0,205 & 0,288 & 0,727 \\
\hline$w_{j}$ & 0,077 & 0,031 & 0,044 & 0,111 \\
\hline
\end{tabular}

Tablo 7. Normalize Karar Matrisi (WEDBA) (Table 7. Normalise Decision Matrix (WEDBA))

\begin{tabular}{c|c|c|c|c}
\hline Kriterler & KRT 1 & KRT 2 & KRT 3 & KRT 4 \\
\hline 2020 & 1 & 0,267 & 1 & 1 \\
\hline 2019 & 0,857 & 0,006 & 0,292 & 0,07 \\
\hline 2018 & 0,854 & 0,559 & 0,417 & 0,363 \\
\hline 2017 & 0,632 & 0,497 & 0,092 & 0,412 \\
\hline 2016 & 0,482 & 0,389 & 0,184 & 0,18 \\
\hline 2015 & 0,388 & 0,475 & 0,18 & 0,332 \\
\hline 2013 & 0,299 & 0,428 & 0,123 & 0,839 \\
\hline 2012 & 0,236 & 0,669 & 0,042 & 0,484 \\
\hline 2011 & 0,161 & 0,443 & 0,047 & 0,332 \\
\hline 2010 & 0,131 & 1 & 0,032 & 0,19 \\
\hline Kriterler & 0,08 & 0,069 & 0,03 & 0,003 \\
\hline & & & & \\
\hline Ylllar & KRT 5 & KRT 6 & KRT 7 & KRT 8 \\
\hline 2020 & & & & 1 \\
\hline 2019 & 0,792 & 0,609 & 0,193 & 0,19 \\
\hline 2018 & 0,716 & 0,575 & 0,183 & 0,832 \\
\hline 2017 & 0,473 & 0,418 & 0,187 & 0,607 \\
\hline 2016 & 0,371 & 0,321 & 0,211 & 0,268 \\
\hline 2015 & 0,288 & 0,26 & 0,227 & 0,119 \\
\hline 2014 & 0,196 & 0,235 & 0,267 & 0,098 \\
\hline 2013 & 0,189 & 0,249 & 0,317 & 0,073 \\
\hline 2012 & 0,102 & 0,201 & 0,634 & 0,048 \\
\hline 2011 & 0,091 & 0,194 & 0,7 & 0,043 \\
\hline 2010 & 0,078 & 0,197 & 1 & 0,029 \\
\hline
\end{tabular}

Tablo 8. Standardize Karar Matrisi (Table 8. Standardized Decision Matrix)

\begin{tabular}{c|c|c|c|c}
\hline Kriterler & KRT 1 & KRT 2 & KRT 3 & KRT 4 \\
\hline 2020 & 1,646 & $-0,623$ & 2,73 & 2,033 \\
\hline 2019 & 1,206 & $-1,579$ & 0,246 & $-1,026$ \\
\hline 2018 & 1,197 & 0,447 & 0,684 & $-0,063$ \\
\hline 2017 & 0,514 & 0,22 & $-0,456$ & 0,099 \\
\hline 2016 & 0,052 & $-0,176$ & $-0,133$ & $-0,664$ \\
\hline 2015 & $-0,237$ & 0,139 & $-0,147$ & $-0,164$ \\
\hline 2013 & $-0,511$ & $-0,033$ & $-0,347$ & 1,503 \\
\hline 2012 & $-0,705$ & 0,85 & $-0,632$ & 0,336 \\
\hline 2011 & $-0,935$ & 0,022 & $-0,614$ & $-0,164$ \\
\hline 2010 & $-1,028$ & 2,062 & $-0,667$ & $-0,632$ \\
\hline Kriterler & $-1,185$ & $-1,348$ & $-0,674$ & $-1,247$ \\
\hline & KRT 5 & KRT 6 & KRT 7 & KRT 8 \\
\hline Yillar & & & & 1,766 \\
\hline
\end{tabular}


Avrupa Bilim ve Teknoloji Dergisi

\begin{tabular}{c|c|c|c|c}
\hline 2019 & 1,265 & 0,884 & $-0,664$ & 1,035 \\
\hline 2018 & 1,025 & 0,749 & $-0,69$ & 1,31 \\
\hline 2017 & 0,259 & 0,124 & $-0,675$ & 0,698 \\
\hline 2016 & $-0,063$ & $-0,263$ & $-0,588$ & $-0,223$ \\
\hline 2015 & $-0,325$ & $-0,506$ & $-0,531$ & $-0,628$ \\
\hline 2014 & $-0,615$ & $-0,606$ & $-0,386$ & $-0,685$ \\
\hline 2013 & $-0,637$ & $-0,55$ & $-0,206$ & $-0,753$ \\
\hline 2012 & $-0,912$ & $-0,741$ & 0,939 & $-0,821$ \\
\hline 2011 & $-0,946$ & $-0,769$ & 1,177 & $-0,834$ \\
\hline 2010 & $-0,987$ & $-0,757$ & 2,26 & $-0,872$ \\
\hline
\end{tabular}

Tablo 9. Sonuçlar (Table 9.Results)

\begin{tabular}{c|c|c|c|c}
\hline Sonuçlar & $\boldsymbol{W E \boldsymbol { D } _ { \boldsymbol { i } } ^ { + }}$ & $\boldsymbol{W E} \boldsymbol{D}_{\boldsymbol{i}}^{-}$ & $\boldsymbol{I S}_{\boldsymbol{i}}$ & Siralama $^{\text {Yillar }}$ \\
\hline 2020 & 0,752 & 1,116 & 0,597 & 1 \\
\hline 2019 & 1,360 & 0,369 & 0,213 & 5 \\
\hline 2018 & 0,786 & 0,758 & 0,491 & 6 \\
\hline 2017 & 0,836 & 0,677 & 0,447 & 9 \\
\hline 2016 & 1,073 & 0,451 & 0,296 & 2 \\
\hline 2015 & 0,943 & 0,579 & 0,380 & 4 \\
\hline 2014 & 0,773 & 0,898 & 0,537 & 8 \\
\hline 2013 & 0,783 & 0,811 & 0,509 & 3 \\
\hline 2012 & 0,995 & 0,545 & 0,354 & 11 \\
\hline
\end{tabular}

Tablo 10. Yöntemlerin Karşılaştırılması (Table 10. Comparison of Methods)

\begin{tabular}{c|c|c|c|c}
\hline \\
\hline 2020 & WEDBA & MOORA & WASPAS & ROV \\
\hline 2019 & 1 & 1 & 1 & 1 \\
\hline 2018 & 5 & 9 & 10 & 8 \\
\hline 2017 & 6 & 2 & 2 & 2 \\
\hline 2016 & 9 & 4 & 3 & 4 \\
\hline 2015 & 7 & 8 & 8 & 7 \\
\hline 2014 & 2 & 7 & 6 & 3 \\
\hline 2013 & 4 & 3 & 4 & 5 \\
\hline 2012 & 8 & 5 & 5 & 6 \\
\hline 2011 & 3 & 10 & 9 & 11 \\
\hline 2010 & 11 & 6 & 7 & 11 \\
\hline
\end{tabular}

Tablo 11. Senaryolar (Table 11. Scenarios)

\begin{tabular}{c|c|c|c|c}
\hline Senaryolar & Senaryo 1 & Senaryo 2 & Senaryo 3 & Senaryo 4 \\
\hline Kriterler & 0,125 & 0,100 & 0,100 & 0,150 \\
\hline$K R T 1$ & 0,125 & 0,300 & 0,200 & 0,150 \\
\hline$K R T$ 2 & 0,125 & 0,100 & 0,100 & 0,200 \\
\hline$K R T 3$ & 0,125 & 0,100 & 0,100 & 0,100 \\
\hline$K R T$ 4 & 0,125 & 0,100 & 0,150 & 0,050 \\
\hline$K R T$ 6 & 0,125 & 0,100 & 0,050 & 0,200 \\
\hline$K R T 7$ & 0,125 & 0,100 & 0,200 & 0,050 \\
\hline$K R T 8$ & 0,125 & 0,100 & 0,100 & 0,100 \\
\hline
\end{tabular}




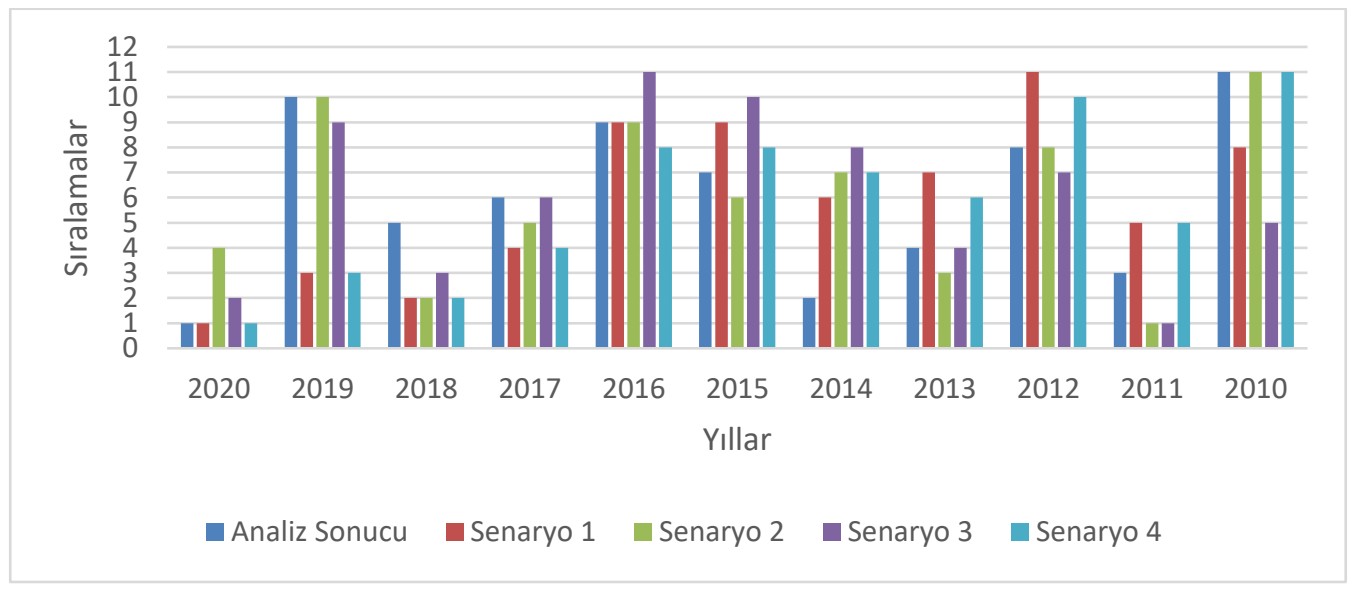

Şekil 1. Senaryo Sonuçları (Figure 1. Scenario Results)

\section{Sonuç}

Bu çalışmada MEREC ve WEDBA yöntemleri kullanılarak Ekol Lojistik firmasının 2010-2020 yılları arasındaki performansı değerlendirilmiştir. Şirketin yıllar bazında performansı şu şekilde sıralanmıştır: $2020>2014>2011>2013>2018>2017>2015>$ $2012>2016>2019>2010$. Analiz sonucu olarak şirketin en iyi performans gösterdiği yıl 2020 yılı olarak belirlenmiştir. Şirketin en kötü performans gösterdiği yıl ise 2010 yılı olarak belirlenmiştir. Çalışmada WEDBA yönteminin doğru sonuçlara ulaşıp ulaşmadığını analiz etmek için yöntemin sonuçları MOORA, WASPAS ve ROV yöntemlerinin sonuçları ile Spearman Korelasyonu kullanılarak karşılaştırılmıştır. Korelasyon sonuçlarına göre WEDBA yöntemi doğru sonuçlara ulaşmıştır. Ayrıca WEDBA yönteminin kriter ağırlıklarındaki değişikliklere duyarlı olduğu duyarlılık analizi ile ortaya konmuştur. $\mathrm{Bu}$ çalışma ile MEREC yöntemi ulusal literatüre tanıtılmıştır. Ayrıca MEREC ve WEDBA yöntemleri literatürde ilk kez birlikte kullanılmıştır. Böylece literatüre katkı sunulmuştur.

$\mathrm{Bu}$ analiz her ne kadar doğru sonuçlar vermiş olsa da veri açısından zayıf bir analizdir. Bu analizde sadece 8 kriter göz önünde bulundurularak yıllar içinde şirketin performansı ölçülmüştür. Daha fazla kriterin göz önünde bulundurulması sonuçların değişmesine sebep olabilir. Gelecek çalışmalar daha fazla kriteri göz önüne alarak daha detaylı bir çalışma yapabilirler. Ayrıca, bu analizde sadece objektif verilerden yararlanılmıştır. Ancak sübjektif verilerde analizi daha kapsayıcı hale getirecektir. Gelecek çalışmalar sübjektif verileri kullanarak daha kapsayıcı bir çalışma ortaya koyabilirler.

\section{Kaynakça}

Aguezzoul, A., \& Pires, S. (2016). 3PL performance evaluation and selection: a MCDM method. In Supply Chain Forum: An International Journal, 17(2), 87-94.

Akpınar, M. E. (2021). Third-Party Logistics (3PL) Provider Selection Using Hybrid Model of SWARA and WASPAS. International Journal of Pure and Applied Sciences, 7(3), 371-382.

Al-Hawari, T., Naji, A., Alshraideh, H., \& Bataineh, O. (2019). Extending the WEDBA to the fuzzy multi-criteria decisione-ISSN: 2148-2683 making environment. International Journal of Computer Applications in Technology, 59(4), 330-346.

Ayaydın, H., Durmuş, S., \& Pala, F. (2017). Gri İlişkisel Analiz Yöntemiyle Türk Lojistik Firmalarında Performans Ölçümü. Gümüshane Üniversitesi Sosyal Bilimler Enstitüsü Elektronik Dergisi, 8(21), 76-94.

Aydın, S., Yörükoğlu, M., \& Kabak, M.(2021). Fourth party logistics firm assessment using a novel neutrosophic MCDM. Journal of Intelligent \& Fuzzy Systems, (Yayın Aşamasında), 1-11.

Basar, M., \& Tolga, A. C. (2020, July). Smart System Evaluation in Vertical Farming via Fuzzy WEDBA Method. In International Conference on Intelligent and Fuzzy Systems (pp. 534-542). Springer, Cham.

Chen, C. T., Pai, P. F., \& Hung, W. Z. (2010). An integrated methodology using linguistic PROMETHEE and maximum deviation method for third-party logistics supplier selection. International Journal of Computational Intelligence Systems, 3(4), 438-451.

Çakır, S., \& Perçin, S. (2013). Çok Kriterli Karar Verme Teknikleriyle Lojistik Firmalarında Performans Ölçümü. Ege Akademik Bakış, 13(4), 449-459.

Demir, G. (2021). Vakıf Üniversitelerinde Akademik Performans Analizi: CRITIC-WEDBA Bütünleşik Model Uygulaması. Uluslararası İktisadi ve İdari Akademik Araştırmalar Dergisi, 1(1), 39-50.

Eren, T., \& Gür, S. (2017). Selection of 3PL company for online shopping sites with AHP and TOPSIS method. Hitit University Journal of Social Sciences Institute, 10(2), 819834.

Fawcett, S. E., \& Cooper, M. B. (1998). Logistics performance measurement and customer success. Industrial Marketing Management, 27(4), 341-357.

Garg, R. (2017). Optimal selection of E-learning websites using multiattribute decision-making approaches. Journal of MultiCriteria Decision Analysis, 24(3-4), 187-196.

Ghorabaee, M. K., Amiri, M., Zavadskas, E. K., Turskis, Z., \& Antucheviciene, J. (2021). Determination of Objective Weights Using a New Method Based on the Removal Effects of Criteria (MEREC). Symmetry, 13(4), 525.

Ghorabaee, M. K. (2021). Assessment of distribution center locations using a multi-expert subjective-objective decisionmaking approach. Scientific Reports, 11(1), 1-19. 
Goswami, S. S., Mohanty, S. K., \& Behera, D. K. (2021). Selection of a green renewable energy source in India with the help of MEREC integrated PIV MCDM tool. Materials Today: Proceedings, (Yayın Aşamasında).

Görener, A. (2009). Kesici Takım Tedarikçisi Seçiminde Analitik Ağ Sürecinin Kullanımı. Journal of Aeronautics and Space Technologies, 4(1), 99-110.

https://www.ekol.com/tr/kurumsal/rakamlarla-ekol-lojistik/ciro/ (Erişim Zamanı: 20/12/2021)

https://www.fortuneturkey.com/fortune500 (Erişim Zamanı: $20 / 10 / 2021)$

Ishizaka, A. (2014). Comparison of fuzzy logic, AHP, FAHP and hybrid fuzzy AHP for new supplier selection and its performance analysis. International Journal of Integrated Supply Management, 9(1-2), 1-22.

Jain, V., \& Ajmera, P. (2019). Application of MADM methods as MOORA and WEDBA for ranking of FMS flexibility. International Journal of Data and Network Science, 3(2), 119-136.

Jayant, A., \& Singh, P. (2015). Application of AHP-VIKOR hybrid MCDM approach for 3PL selection: a case study. International Journal of Computer Applications (IJCA), 125(5), 4-11.

Jovčić, S., \& Průša, P. (2021). A Hybrid MCDM Approach in Third-Party Logistics (3PL) Provider Selection. Mathematics, 9(21), 2729.

Khan, S. A., Ahmed, W., \& Ubaid, A. (2020, October). A Decision Support System for Logistics Performance Evaluation of Courier Company. In 2020 5th International Conference on Logistics Operations Management (GOL) (pp. 1-5). IEEE.

Kısa, A. C. G., \& Ayçin, E. (2019). OECD Ülkelerinin Lojistik Performanslarının SWARA Tabanlı EDAS Yöntemi ile Değerlendirilmesi. Çankırı Karatekin Üniversitesi İktisadi ve İdari Bilimler Fakültesi Dergisi, 9(1), 301-326.

Li, Y. L., Ying, C. S., Chin, K. S., Yang, H. T., \& Xu, J. (2018). Third-party reverse logistics provider selection approach based on hybrid-information MCDM and cumulative prospect theory. Journal of Cleaner Production, 195, 573584.

Mercangoz, B. A., Yildirim, B. F., \& Yildirim, S. K. (2020). Time period based COPRAS-G method: application on the Logistics Performance Index. LogForum, 16(2).

Özbek, A., \& Eren, T. (2012). Üçüncü parti lojistik (3PL) firmanın analitik hiyerarşi süreciyle (AHS) belirlenmesi. International Journal of Engineering Research and Development, 4(2), 4654.

Rao, R. V., \& Singh, D. (2011). Evaluating flexible manufacturing systems using Euclidean distance-based integrated approach. International Journal of Decision Sciences, Risk and Management, 3(1-2), 32-53.

Rao, R. V., \& Singh, D. (2012). Weighted Euclidean distance based approach as a multiple attribute decision making method for plant or facility layout design selection. International Journal of Industrial Engineering Computations, 3(3), 365-382.

Rezaei, J., van Roekel, W. S., \& Tavasszy, L. (2018). Measuring the relative importance of the logistics performance index indicators using Best Worst Method. Transport Policy, 68, 158-169.

Senir, G. (2021). Comparison of Domestic Logistics Performances of Turkey and European Union Countries in 2018 With an Integrated Model. LogForum, 17(2), 193-204.
Ulutaş, A. (2021). A grey hybrid model to select the optimal thirdparty logistics provider. South African Journal of Industrial Engineering, 32(1), 171-181.

Ulutaş, A. (2020). Stacker Selection with PSI and WEDBA Methods. International Journal of Contemporary Economics and Administrative Sciences, 10(2), 493-504.

Ulutaş, A. (2019). Entropi Tabanlı EDAS Yöntemi ile Lojistik Firmalarının Performans Analizi. Uluslararast Iktisadi ve Ídari İncelemeler Dergisi, (23), 53-66.

Yalçın, B., \& Ayvaz, B. (2020). Çok Kriterli Karar Verme Teknikleri ile Lojistik Performansin Değerlendirilmesi. Istanbul Ticaret Üniversitesi Fen Bilimleri Dergisi, 19(38), 117-138.

Yuan, Y., Xu, Z., \& Zhang, Y. (2021). The DEMATEL-COPRAS hybrid method under probabilistic linguistic environment and its application in Third Party Logistics provider selection. Fuzzy Optimization and Decision Making, 1-20. 